\title{
Investigation of the Concentration of Air Pollutants in Ambient Air of Babol City
}

\author{
Seyede Houriye Fallah, ${ }^{1}$ Hossein Ali Asgharnia, ${ }^{1}$ Abdoliman Amouei, ${ }^{1}$ Ali Akbar Mohammadi, ${ }^{2,}$ and \\ Soghra Mehdipoor ${ }^{3}$ \\ ${ }^{1}$ Department of Environmental Health Engineering, Faculty of Paramedical Sciences, Babol University of Medical Sciences, Babol, IR Iran \\ ${ }^{2}$ Department of Environmental Health Engineering, Neyshabur University of Medical Sciences, Neyshabur, IR Iran \\ ${ }^{3}$ Student Research Committee, Babol University of Medical Sciences, Babol, IR Iran \\ "Corresponding author: Ali Akbar Mohammadi, Department of Environmental Health Engineering, Neyshabur University of Medical Sciences, Neyshabur, IR Iran. E-mail: \\ mohammadi.eng73@gmail.com
}

Received 2018 May 23; Accepted 2018 June 03.

\begin{abstract}
Background: The air quality and its impact on the environment, especially on human health, are considered as a significant issue of concern by major public and governmental organizations. Therefore, monitoring of air pollutants is necessary to design control plans. This study aimed to evaluate the criteria for pollutants in the ambient air of Babol city.

Methods: This descriptive and cross-sectional study was conducted on 136 samples obtained from 17 sampling stations during 2013, and the samples were collected using the respective devices on the site. The data were analyzed by ANOVA using Excel and SPSS software. Then, the results were compared with the national environmental protection agency (EPA) standards.

Results: Among the samples obtained from 8 sampling stations, the maximum mean concentration of particulate matter (PM) was $0.0285 \pm 0.007 \mu \mathrm{g} / \mathrm{m}^{3}$ in Shohada square, and the minimum was $0.024 \pm 0.009 \mu \mathrm{g} / \mathrm{m}^{3}$ at the station at Mohammad Hassan Khan bridge; these are lower than the standard values. Also, the amount of carbon monoxide, nitrogen dioxide, and sulfur dioxide in all stations was zero, so the air quality index (AQI) was less than 50 in all cases.

Conclusions: The findings of this research show that the measured concentration of particles and other pollutants was less than the EPA and WHO standards; therefore, Babol has clean and healthy air.
\end{abstract}

Keywords: Air Pollution, Air Quality Index (AQI), Particulate Matter (PM)

\section{Background}

Today, one of the most important environmental problems in the major cities of the world is poor air quality. The adverse air conditions cause a wide range of acute and chronic health effects, even leading to death due to respiratory and cardiovascular diseases $(1,2)$. Air pollution accounted for $6 \%$ of the total mortality or more than 40,000 cases per year in Austria, Switzerland, and France (3). Important pollutants such as carbon monoxide (CO), particulate matter $(\mathrm{PM})$, sulfur oxides $\left(\mathrm{SO}_{\mathrm{x}}\right)$, and nitrogen oxides $\left(\mathrm{NO}_{\mathrm{x}}\right)$ are not part of the natural composition of air, and thus, their presence in the atmosphere is the result of industrial development, population growth, increased use of energy sources, and so on (1).

Epidemiological studies at a university of the United Kingdom have shown the relationship between particulate air pollution and disease exacerbation, with a rise in the disease not confined to people with respiratory illness and, also, an increase in the number of deaths from cardiovascular and respiratory diseases among the elderly. Harvard University in the United States conducted a study in six cities and indicated that long-term air pollution is associated with traffic and mortality (4).

Another study in the Netherlands illustrated the direct relationship between long-term exposure to air pollution and increased mortality (5). Scientists found that PM could increase the oxidized phospholipids in the lungs, resulting in a systemic cellular inflammatory response (6).

Conclusive evidence has indicated that air pollution increases the risk of cardiovascular diseases. Exposure to air pollution is related to activation of inflammatory pathways, endothelial injury and dysfunction, production of reactive oxygen species, changes in blood coagulation factors, and arterial vasoconstriction (7).

Since infants and children breathe much faster than adults do, they are exposed more to air pollutants than adults. This increases their contact with any pollutant in 
the air. Moreover, children are more sensitive to the effects of air pollution on their immune system as the body organs are not fully developed (8).

Also, $\mathrm{CO}, \mathrm{NO}_{2}, \mathrm{SO}_{2}$, and the total concentration of PM during the first trimester of pregnancy are risk factors for low birth weight infants (9).

Since the air quality directly affects the health of people, awareness regarding the air quality is considered as one of the basic rights of people. On the one hand, one of the duties of the Ministry of Health is to provide for and maintain and improve the public health and on the other hand, to know the effects of air pollutants and the exposure of citizens to them.

\section{Objectives}

In the current study, we aimed to investigate the air quality index (AQI), considering that no research has been carried out in this field so far.

\section{Methods}

This non-interventional, descriptive, and crosssectional study was conducted in Babol in 2013. Babol is divided into four districts. There are 2 stations in each district, and 17 samples were collected from each station. Totally, 136 samples were collected during the year. As the maximum pollution in Babol city was expected to be in the central squares due to the heavy traffic and car volumes and high pollution, most of the samples were collected at different hours of the day and on different days of the week from the main squares.

Along with the device (The devices used for air pollution measurement were thermometers and humidity meters), temperature and humidity sensors were used. It was easy to calculate the standard conditions, and these were included in the measurements. Micro Dust Pro, Cassella, UK, instrument was used to measure the concentration of the inhaled particles whose aerodynamic diameter was less than 10 microns. This instrument was designed to measure the concentration of the inhalable particles and the mean particle density every 10 seconds.

The measured values were transferred to a computer and analyzed. This instrument can be used for sampling of different types of dust. The instrument is equipped with a polyurethane filter and a pump for sampling particulate matter. The airflow rate was $2 \mathrm{~L} / \mathrm{min}$. Finally, the mass concentration of $\mathrm{PM}_{10}$ was calculated using a standard gravimetric procedure.

The data were analyzed by ANOVA using Excel and SPSS software. The concentration of the pollutants was compared with the United States environmental protection agency (EPA) standard using the standard table of clean air, and then, the air quality was determined in accordance with the related standard $(10,11)$.

\section{Results}

The levels of $\mathrm{CO}, \mathrm{NO}_{2}$, and $\mathrm{SO}_{2}$ at all stations were close to zero (Table 1 ). The maximum mean concentration of PM was $0.0285 \pm 0.007 \mu \mathrm{g} / \mathrm{m}^{3}$ in Shohada square, and the minimum was $0.024 \pm 0.009 \mu \mathrm{g} / \mathrm{m}^{3}$ at the station at Mohammad Hassan Khan bridge; these are lower than the standard values.

Also, the PM concentration was highest at 18:00 - 20:00 hours and lowest at 14:00 - 16:00 hours, being 0.0286 \pm $0.087 \mu \mathrm{g} / \mathrm{m}^{3}$ and $0.0195 \pm 0.0091 \mu \mathrm{g} / \mathrm{m}^{3}$, respectively (Table 2). Moreover, regarding the relationship between the PM concentration and days of the week, the highest concentration of PM, $0.028 \pm 0.0079 \mu \mathrm{g} / \mathrm{m}^{3}$, was seen on Wednesday, and the lowest, $0.244 \pm 0.0085 \mu \mathrm{g} / \mathrm{m}^{3}$, was seen on Friday (Table 3).

\section{Discussion}

The maximum mean concentration of $\mathrm{PM}_{10}$ was 0.0285 ppm in Shohada square whereas the minimum was 0.024 ppm at the station at Mohammad Hassan Khan bridge; these concentrations are lower than the standard values. The concentration was highest at 18:00 - 20:00 hours and lowest at 14:00 - 16:00 hours.

Regarding the relationship between the PM concentration and weekdays, the highest concentration of PM was seen in the middle days of the week, and the lowest was at the end days of the week. In 2006, a maximum 24-hour concentration of $\mathrm{PM}_{10}$ was $150 \mathrm{ppm}$ according to the EPA standard whereas the WHO 24-hour standard is $50 \mu \mathrm{g} / \mathrm{m}^{3}$. In both cases, the amount of PM was lower than the standards $(10,12)$.

Shahsavani et al. evaluated the PM concentrations in Ahvaz in 2010 and concluded that the mean concentration of $\mathrm{PM}_{10}$ was $319.6 \pm 407.7 \mu \mathrm{g} / \mathrm{m}^{3}$. The maximum amount of $\mathrm{PM}_{10}$ was $496 \mu \mathrm{g} / \mathrm{m}^{3}$, which was due to large amounts of dust originating from the deserts of Iraq (13).

In a study by Leili et al. on the PM concentration and air quality of Tehran in 2006 - 2007, it was reported that the minimum and maximum concentrations of PM at 5 stations in Tehran was 55.31 and $67.76 \mu \mathrm{g} / \mathrm{m}^{3}$, respectively. According to the EPA standard, $67 \%$ and $25 \%$ of the measurements were higher than the standard at stations 1 and 2 (14).

Another study on AQI and PM concentration in Arak reported the minimum and maximum concentration of 


\begin{tabular}{|c|c|c|c|c|c|c|}
\hline \multirow{2}{*}{ Days of the Week } & \multirow{2}{*}{ No. of Samples } & \multicolumn{5}{|c|}{ PM Level, ppm } \\
\hline & & Minimum & \multicolumn{2}{|c|}{ Maximum } & Mean & SD \\
\hline Saturday & 16 & 0 & 0 & & 0 & 0 \\
\hline Sunday & 32 & 0 & 0 & & 0 & 0 \\
\hline Monday & 24 & 0 & 0 & & 0 & 0 \\
\hline Thursday & 15 & 0 & 0 & & 0 & 0 \\
\hline Wednesday & 24 & 0 & 0 & & 0 & 0 \\
\hline Thursday & 26 & 0 & 0 & & 0 & 0 \\
\hline Friday & 32 & 0 & 0 & & 0 & 0 \\
\hline \multirow{2}{*}{ Hours of the Day } & \multirow{2}{*}{ No. of Samples } & \multicolumn{5}{|c|}{ PM Level, $\mu \mathrm{g} / \mathbf{m}^{3}$} \\
\hline & & Minimum & Maximum & Mean & & SD \\
\hline $6-8$ & 30 & 0.012 & 0.040 & 0.0269 & & 0.0064 \\
\hline $8-10$ & 25 & 0.015 & 0.039 & 0.0266 & & 0.0067 \\
\hline $10-12$ & 17 & 0.009 & 0.034 & 0.0258 & & 0.0073 \\
\hline $12-14$ & 9 & 0.009 & 0.047 & 0.0282 & & 0.0011 \\
\hline $14-16$ & 17 & 0.005 & 0.038 & 0.0195 & & 0.0091 \\
\hline $16-18$ & 15 & 0.015 & 0.041 & 0.028 & & 0.0075 \\
\hline $18-20$ & 23 & 0.010 & 0.040 & 0.0286 & & 0.0087 \\
\hline \multirow{2}{*}{ Days of the Week } & \multirow{2}{*}{ No. of Samples } & \multicolumn{5}{|c|}{ PM Level, $\mu \mathbf{g} / \mathbf{m}^{3}$} \\
\hline & & Minimum & Maximum & Mean & & SD \\
\hline Saturday & 8 & 0.012 & 0.047 & 0.025 & & 0.0102 \\
\hline Sunday & 18 & 0.007 & 0.039 & 0.026 & & 0.009 \\
\hline Monday & 10 & 0.009 & 0.041 & 0.025 & & 0.0087 \\
\hline Thursday & 15 & 0.020 & 0.037 & 0.027 & & 0.0056 \\
\hline Wednesday & 18 & 0.013 & 0.040 & 0.028 & & 0.0079 \\
\hline Thursday & 41 & 0.009 & 0.040 & 0.026 & & 0.0080 \\
\hline Friday & 26 & 0.005 & 0.0037 & 0.0024 & & 0.0085 \\
\hline
\end{tabular}

$\mathrm{PM}_{10}$ to be 34.33 and $100.1 \mu \mathrm{g} / \mathrm{m}^{3}$, respectively. The cleanest air conditions were in December, and the highest levels of PM were in June, which is contrary to the results of the current study because Arak has heavy industries and is a desert with high sandy wind and pollution (15).

The results of a study in Sri Lanka in 2012 on the concentration of pollutants in the residential and central areas of the city showed that the concentration of PM in the residential areas was greater than that in the central parts (16).

Based on the results of the present study, the levels of $\mathrm{CO}, \mathrm{NO}_{2}$, and $\mathrm{SO}_{2}$ at all stations were close to zero, which is lower than the standard. One of the most important pollutants entering into the atmosphere via transportation of vehicles is $\mathrm{CO}$.

However, the CO level was zero in the numerous measurements performed at the stations as most of the measurements were carried out at the height of $1.5 \mathrm{~m}$ from the ground. Since CO moves rapidly into the air after release with respect to the temperature, the zero levels measured is expectable. But this result is different from that of Naddafi in Tehran in 2009 since Tehran has the largest number of vehicles and industries in the suburb, and the geographical location of Tehran causes the high concentra- 


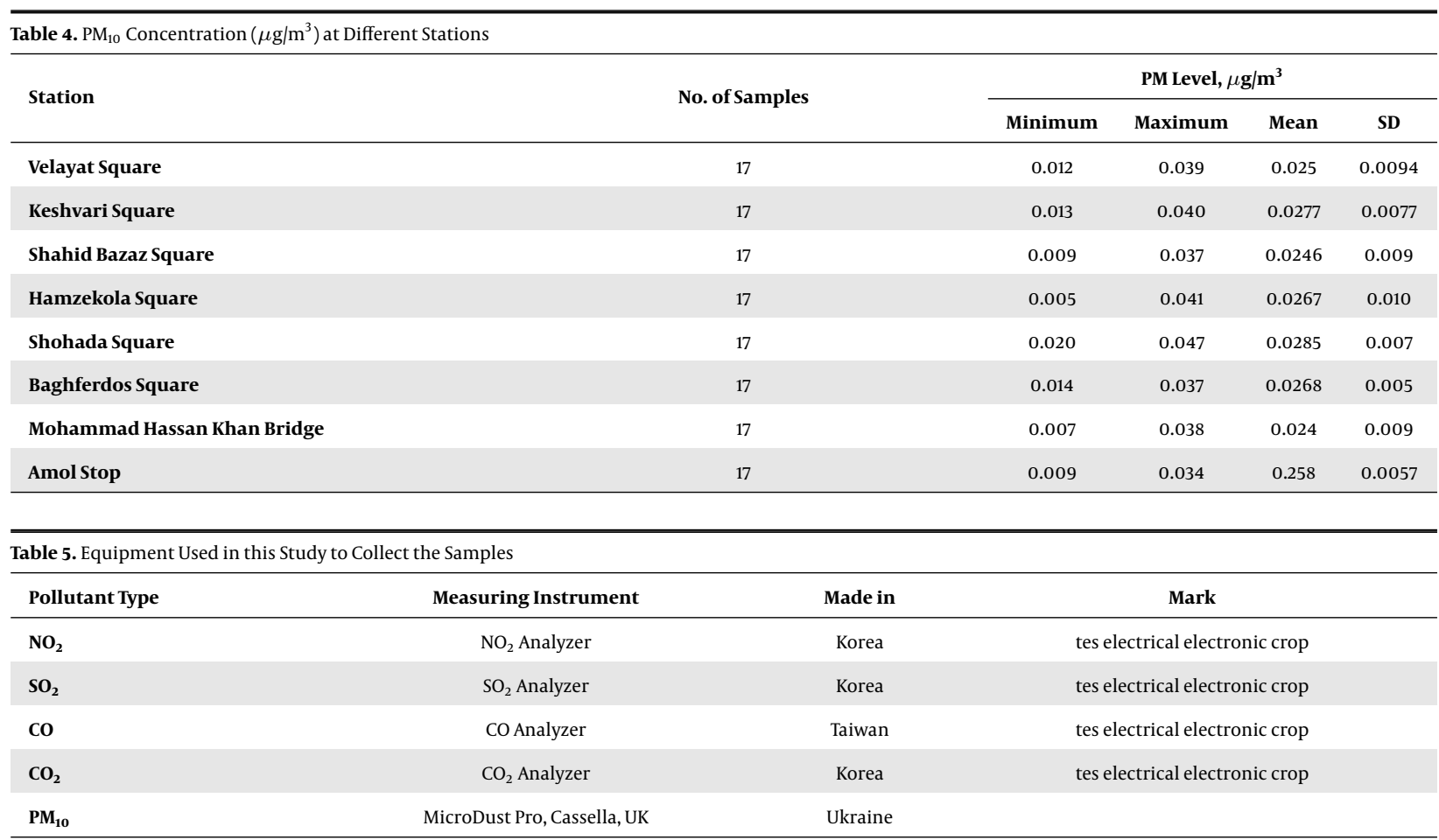

tion of CO while there are no such conditions in Babol (17).

The AQI of Babol was lower than the standard, and the percentage of measured days was clean air $(A Q I<50)$. In a study titled "The comparison of air quality between Tehran and Isfahan and some suggested strategies for its improvement in 1999," the air quality in these two cities was determined using the standard pollutant index, and the concentration of the pollutants according to the calculated index was 329 days in Tehran and 34 days in Isfahan, which exceeded the standard (18).

Another study compared the air quality in Tehran in 2006, 2007, and 2008 and demonstrated that the AQI was higher and lower than the standard (AQI < 100) in 71.5\% (261 days) and 28\% (104 days) of the cases in 2006, respectively.

The AQI was higher and lower than the standard in $59.72 \%$ (218 days) and $40.28 \%$ (147 days) of the cases in 2007 , respectively (19).

Rafieinia et al. conducted a study titled "Comparative investigation of health quality of air in Tehran, Isfahan and Shiraz metropolises in 2011 - 2012" and illustrated that the AQI in Tehran, Isfahan, and Shiraz was higher than the EPA standard of Iran (AQI > 100) for 341, 323, and 85 days, respectively, and PM was a major pollutant in these cities on most days (20).

\subsection{Conclusion}

The measured values at all stations were lower than the standards of the EPA, which indicates that the air of Babol is clean, but considering the importance of the issue of air pollution and the limitations of the current research, it is better to perform further research on organic pollutants such as BTXE and other pollutants.

\section{Acknowledgments}

The authors would like to thank the Vice Chancellor of Research and Technology in Babol University of Medical Sciences and to Reyhaneh Barari for translating the article into English.

\section{References}

1. [No authors listed]. Health effects of outdoor air pollution. Part 1. Committee of the Environmental and Occupational Health Assembly of the American Thoracic Society. Am J Respir Crit Care Med. 1996;153(2):477-98. doi: 10.1164/ajrccm.153.2.8564086. [PubMed: 8564086].

2. Health Effect Institue. Understanding the health effects of components of the particulate matter mix:progress and next step. Boston, USA: HEI Prespectives. Health effects Institue; 2002.

3. Kunzli N, Kaiser R, Medina S, Studnicka M, Chanel O, Filliger P, et al. Public-health impact of outdoor and traffic-related air pollution: a European assessment. Lancet. 2000;356(9232):795-801. doi: 10.1016/S0140-6736(00)02653-2. [PubMed: 11022926]. 
4. Seaton A, MacNee W, Donaldson K, Godden D. Particulate air pollution and acute health effects. Lancet. 1995;345(8943):176-8. [PubMed: 7741860].

5. Beelen. R, Hoe G, Fischer P, van den Brandt PA, Brunekreef B. Estimated long-term outdoor air pollution concentrations in a cohort study. Atmospheric Env. 2007;41(7):1343-58.

6. Kampfrath T, Maiseyeu A, Ying Z, Shah Z, Deiuliis JA, Xu X, et al. Chronic fine particulate matter exposure induces systemic vascular dysfunction via NADPH oxidase and TLR4 pathways. Circ Res. 2011;108(6):71626. doi: 10.1161/CIRCRESAHA.110.237560. [PubMed: 21273555]. [PubMed Central: PMC3085907].

7. Baccarelli A, Zanobetti A, Martinelli I, Grillo P, Hou L, Giacomini S, et al. Effects of exposure to air pollution on blood coagulation. JThromb Haemost. 2007;5(2):252-60. doi: 10.1111/j.1538-7836.2007.02300.x. [PubMed: 17083648].

8. Pishkar A, Tavakoli K, Jazeiri SR. Ambient air pollution and health risks its related on children. Ninth National Conference on Environmental Health. 2005

9. Ha EH, Hong YC, Lee BE, Woo BH, Schwartz J, Christiani DC. Is air pollution a risk factor for low birth weight in Seoul? Epidemiology. 2001;12(6):643-8. [PubMed: 11679791].

10. United States Environmental Protection Agency (USEPA). National ambient air quality standards. USA: United States Environmental Protection Agency; 1990.

11. Ministry of Health and Medical Education. A guide to calculation, determination and announcement of Air Quality Index. Iran: Environmenta and Occupational Center, Institute for Environment research; 2012. Persian.

12. World Health Organization. Air quality guidelines: global update 2005. Copenhagen: World Health Organization; 2006.
13. Shahsavani A, Naddafi K, Jafarzade Haghighifard N, Mesdaghinia A, Yunesian M, Nabizadeh R, et al. The evaluation of PM10, PM2.5, and PM1 concentrations during the Middle Eastern Dust (MED) events in Ahvaz, Iran, from april through september 2010. J Arid Env. 2012;77:7283. doi: 10.1016/j.jaridenv.2011.09.007.

14. Leili M, Naddafi K, Nabizadeh R, Yunesian M, Mesdaghinia A. The study of TSP and PM10 concentration and their heavy metal content in central area of Tehran, Iran. Air Quality, Atmosphere \& Health. 2008;1(3):15966. doi: 10.1007/s11869-008-0021-z.

15. Fazelinia F, Khodabandehlou AA, Rafati L, Mahvi AH. Investigation of Air Quality Index and PM10 and PM2.5 in Arak. Iranian Journal Of Health Sciences. 2013;1(3):12-7. doi:10.18869/acadpub.jhs.1.3.12.

16. Nandasena S, Wickremasinghe AR, Lee K, Sathiakumar N. Indoor fine particle (PM2.5) pollution exposure due to secondhand smoke in selected public places of Sri Lanka. Am J Ind Med. 2012;55(12):112936. doi: 10.1002/ajim.22040. [PubMed: 22473526]. [PubMed Central: PMC3432657].

17. Naddafi K, Sowlat M, Safari M. Integrated assessment of air pollution in tehran, over the period from september 2008 to september 2009. Iran J Public Health. 2012;41(2):77-86. [PubMed: 23113138]. [PubMed Central: PMC3481676].

18. Khorasani N, Cheraghi M, Nadafi K, Karami M. [The comparison of Tehran and Esfehan air quality and some strategies are suggested for its improvement in 1378]. Iran J Nat Res. Persian.

19. Nadafi K, Heidari M, Hasanvand MS, Qaderpoor M. The comparison of Tehran air quality in 1385-1386. 11 National Congrees on Environmental Health 2008. Zahedan. 2008. Persian.

20. Rafieinia H, Kermani M, Aghai M, Bahramiasl F, Karimzade S. [The comparison of Tehran, Esfehan and Shiraz air quality during 2011]. $j$ Health in field. 2012;1(4):37-44. Persian. 